\title{
PARTICULATE MATTER EMISSION REDUCTION FROM MARINE DIESEL ENGINES BY ELECTROHYDRODYNAMIC METHODS
}

\author{
Arkadiusz T. Sobczyk, Anatol Jaworek, Artur Marchewicz, Andrzej Krupa, Tadeusz Czech \\ Institute of Fluid Flow Machinery, Polish Academy of Sciences \\ Fiszera Street 14, 80-231 Gdansk, Poland \\ tel.: +48583411271, fax: +48583416144 \\ e-mail: arkadiusz.sobczyk@imp.gda.pl,artur.marchewicz@imp.gda.pl \\ anatol.jaworek@imp.gda.pl,andrzej.krupa@imp.gda.pl,tadeusz.czech@imp.gda.pl
}

\author{
Lukasz Śliwiński \\ RAFAKO S.A., Dedusting Installations Division \\ Górnośląska Street 3A, 43-200 Pszczyna, Poland \\ tel.: +48 32 3263026, fax: +48324153427 \\ e-mail: lukasz.sliwinski@rafako.com.pl \\ Adam Charchalis \\ Gdynia Maritime University, Faculty of Marine Engineering \\ Morska Street 81-87, 81-225 Gdynia, Poland \\ tel.: +4858 5586347, fax: +48585586399 \\ e-mail: a.charchalis@wm.umg.edu.pl
}

\begin{abstract}
Particulate matter (PM) and gaseous compounds $\left(\mathrm{SO}_{2}, \mathrm{NOx}, \mathrm{VOC}\right)$ emitted by diesel engines causes serious global environmental problems and health impact. Despite numerous evidences about the harmfulness of diesel particles, the PM emission by diesel engines used by ships, cars, agricultural machines, or power generators is still unregulated, and the efficient removal of PM from diesel exhausts is still the major technological challenge. In order to comply with the International Maritime Organization regulation, the NOx emission is reduced by using selected catalytic reactor, and sulphur oxide emission has been reduced by using fuels of low sulphur content. However, both of those measures cannot be used for the reduction of PM emission produced during combustion of marine fuels. The lack of appropriate regulations results from insufficiently developed technology, which could remove those particles from exhaust gases. Conventional scrubbers currently available on the market remove only sulphur oxide with required collection efficiency, but the collection efficiency for PM2.5 is below 50\%. The article discusses the technical means used for the removal of PM from marine diesel engines via applying electrohydrodynamic methods, in particular electrostatic agglomeration, as a method of nanoparticles coagulation to larger agglomerates, which could operate in two-stage electrostatic precipitation systems, and electrostatic scrubbers, which remove particles by electrically charged water droplets. The experimental results were obtained for a 2-stroke $73 \mathrm{~kW}$ diesel engine fuelled with marine gas oil $(M G O)$. The agglomerator allowed increasing the collection efficiency from diesel exhausts for PM2.5 particles by about $12 \%$, compared to electrostatic precipitator operating without agglomerator, and the total mass collection efficiency was above 74\%. The collection efficiency of electrostatic scrubber was higher than 95wt.\%. The advantage of using the electrostatic scrubber is that it can also reduce the $\mathrm{SO}_{2}$ emission by more than 90\%, when HFO is used.
\end{abstract}

Keywords: exhaust gases, marine diesel engines, particulate matter (PM), scrubber

\section{Introduction}

The marine transport is the most important means of long-distance international trade of industrial products, foodstuff, raw materials, and fuels, but it remains the largest source of 
atmospheric pollution. The composition of exhaust gases emitted by ships strongly depends on parameters of ship engine. For example, until 2015, when HFO of 3.5\% sulphur content was available at bunkers, the typical emission of ship engine of a power of $5 \mathrm{MW}$, by $20 \%$ load, was $5-8 \% \mathrm{CO}_{2}, 10-13 \% \mathrm{O}_{2}, 5 \% \mathrm{H}_{2} \mathrm{O}, 75 \% \mathrm{~N}_{2}$, some noxious gases, like, NOx (1500 ppm), $\mathrm{SO}_{2}$ (600-750 ppm), VOC (180 ppm), and particulate matter (PM) of a concentration higher than $100 \mathrm{mg} / \mathrm{m}^{3}$.

However, new IMO regulation, which come into force after 1 January 2020, limit the sulphur content of any fuel oil used on board to a level of $0.5 \mathrm{wt} . \%$, and to $0.1 \mathrm{wt} . \%$ in the zones called Emission Control Areas (ECA). After that time, ship owners and operators have the following 3 main options to comply with the IMO 2020 sulphur limit:

- to use alternative fuels, for example, biodiesel, Liquefied Natural Gas (LNG) or methanol instead of marine oil, or propel ship with electricity,

- to use fuel with sulphur content not higher than $0.50 \mathrm{wt} . \%$, and $0.1 \mathrm{wt} . \%$ at the ECA,

- to install exhaust gas cleaning systems, for example, dry or water scrubbers.

The first two options are expensive and require high financial investment costs, because significant modification of ships would be needed, or even a new vessel would be bought. By the third option, the same engine can be fuelled with cheaper oil, and only lower investments will be required to the installation of exhaust gas cleaning system, which could remove pollution from exhaust gas before it will be released into the atmosphere [1].

Although the reduction of SOx emission by ships has been solved by the obligation of lowsulphur fuel combustion, the emission of PM can only be reduced insignificantly by this way. For this reason, IMO postponed the regulations until new efficient and economic technology will be available.

Currently, the efficient removal of PM from diesel exhausts produced by marine diesel engine is still the major technological challenge in environment protection. PM, similar to SOx, emitted from diesel engines has caused serious health and environmental problems. Primary particles present in exhaust gases have a complex structure, and their size ranges from few to tens nanometres. The chemical composition of these particles depends on the kind of fuel, the kind of engine and operating parameters. The main compounds of diesel exhaust particles are soot, sulphur compounds, organic compounds, and trace metals. Due to low collection efficiency of conventional gas cleaning devices for PM1 particles, a large fraction of these compounds is released to the atmosphere.

A combination of engine modifications and after treatment technologies is suggested to achieve compliance with future legislative limits [2].

In ideal combustion conditions, the hydrocarbons forming the fuel should be converted to water vapour and carbon dioxide. However, due to local oxygen deficit, some of the fuel vapours or products of thermal decomposition of the fuel undergo pyrolysis, and as an effect, unsaturated hydrocarbons, polyacetylenes and polycyclic aromatic hydrocarbon can be generated. These molecules are considered as precursors for the nucleation of soot [3]. Due to growth process of soot, surface absorption of unburned constituents of fuels, lubricants, and oxidized sulphur, the small particles of soot linked together in the shape of chain forming particulate matter.

The article discusses the technical means used for the PM removal from marine diesel engines by using electrohydrodynamic methods, in particular electrostatic scrubbers, and electrostatic agglomerators, as new methods of nanoparticles coagulation to larger agglomerates, operating in two-stage electrostatic precipitation systems.

\section{Methods of PM emission reduction}

The PM number concentration in Diesel exhaust varies within $10^{7}$ to $10^{9}$ particles $/ \mathrm{cm}^{3}$ and depends on engine speed. Increasing engine speed causes an increase in the number concentration 
of particles and decrease in their geometric mean diameter [4]. An example of particles deposited on the inner surface of exhaust pipeline is shown in Fig. 1.

Due to physical and chemical properties of these particles, their removal from exhaust gases became a real concern in recent years. There are many methods available to reduce of PM emission, which have been applied in marine vessels. These methods include fuel born catalyst, low-sulphur marine fuel, emulsified diesel oil, liquefied natural gas fuel, exhaust gas Venturi scrubbers, diesel particulate filter (DPF), fuel borne catalyst combined with DPF (FBC+DPF), and distillate fuel oil combined with catalysed DPF (distillate fuel oil + CDPF) [5, 6]. Fuel born catalyst has the lowest reduction of PM emission (35\%). For example, the reduction of PM emission using Venturi scrubber, LNG 94\%, FBC+DPF and distillate fuel oil + CDPF is higher than $90 \%[5,6]$.

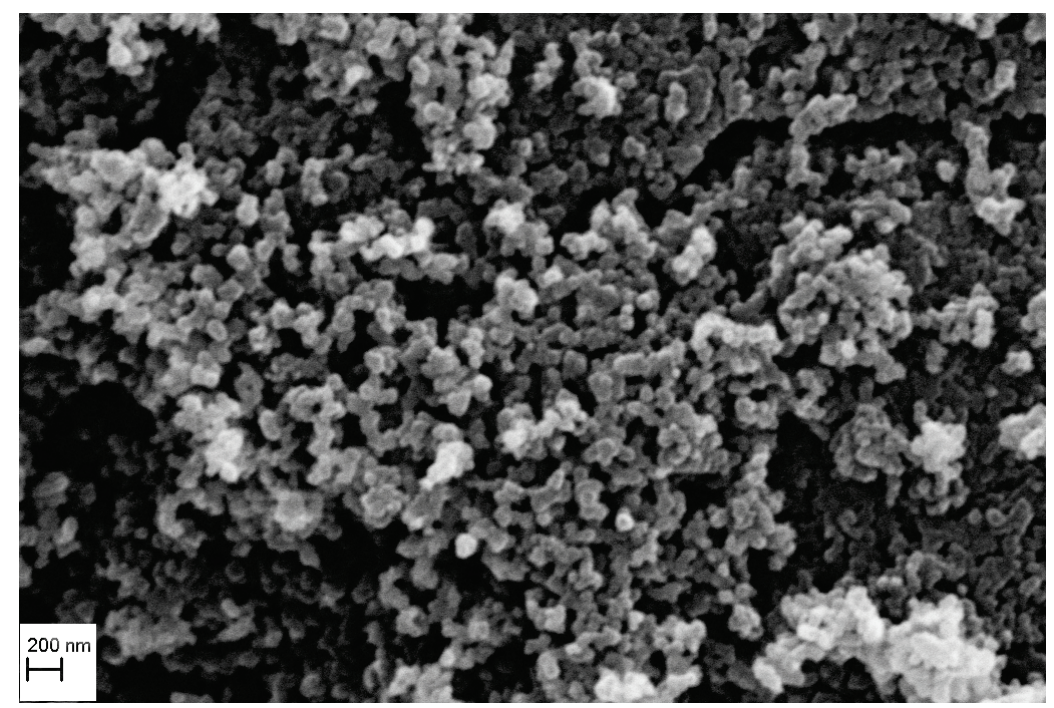

Fig. 1. SEM micrograph of soot deposited in the exhaust pipeline after Diesel engine

\subsection{Scrubbing}

There are two major types of scrubber technologies: the dry scrubber and the wet scrubber. In dry scrubbers, a sprayed liquid is a solution or slurry of alkaline materials, which evaporated after contact with flue gases. The result of dry scrubber processing is precipitated salts, dried solids and few percent of free moisture.

Inertial scrubber is a device in which dust particles conveyed by exhaust gases are captured by sprayed water droplets. Typical scrubber is a vertical chamber in which liquid, usually water, is sprayed at the top of scrubber chamber by an atomizer (nozzle). The exhaust gas enters the chamber at the bottom so that the gas flows upwards, while water flows down. During this process, dust particles are deposited onto droplets due to their inertia. Most frequently, the classical "counter-current" scrubber configuration is used in practice (Fig. 2a)

Wet scrubbing is the most widely used technology for flue gas desulfurization. First, it was used in coal-fired power stations, but now has been successfully applied in maritime transport. However, the removal of PM from gases by the scrubbing process is much difficult than gas desulfurization. The collection of PM during scrubbing occurs due to collision between fine particles and droplets and efficiency of this process is depended of scrubber geometry, gas and liquid velocities, dust particles size, droplet size distribution, droplet dispersion, and the fraction of liquid flowing as a film on the walls and others elements of scrubber [7]. Scrubbers used in coalfired power plants have the collection efficiency in the range of 70 to $99 \%$ for particle size larger than 1 micron, but only about $50 \%$ for particle size smaller than 1 micrometre [8]. The diesel particles are usually smaller than 1 micrometre. 

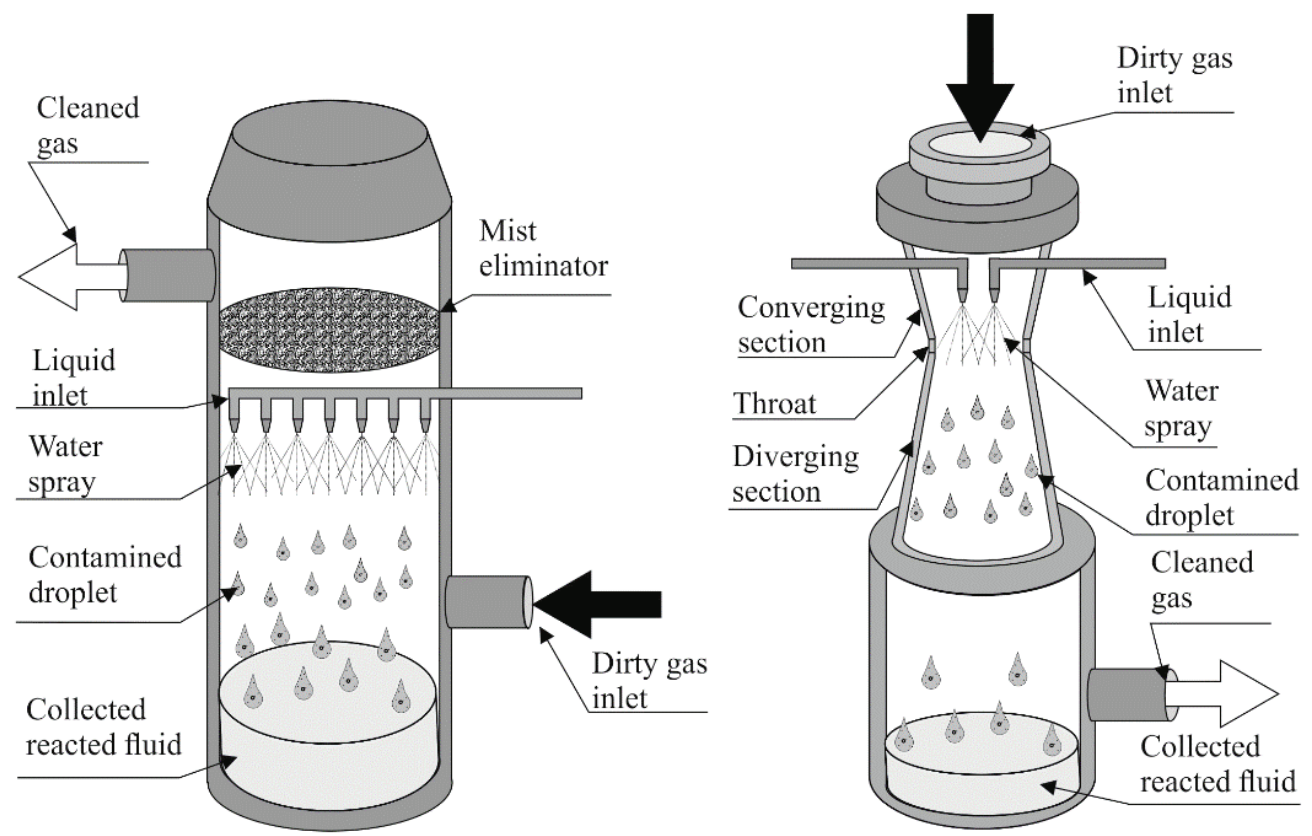

Fig. 2. Schematic of inertial counter-flow wet scrubber (left) and Venturi scrubber (right)

Venturi scrubbers allows to obtain much higher collection efficiency for particles above submicron size (over 90\% [5]) due to high gas velocity in the Venturi throat (Fig. 2b), but the pressure drop in reactor chamber is relatively high (up to $15 \mathrm{kPa}$ ). However, Venturi scrubbers are ineffective for submicron particles, and their collection efficiency is not higher than $70 \%$.

The high inlet gas temperature, high water temperature, low $\mathrm{pH}$ and high chlorine content from sea water used for the scrubbing, needs metal, corrosion resistant materials for scrubber construction [9], which increases the cost of scrubbers, but this cost is still lower than using fuel with lower sulphur content.

\subsection{Electroscrubbing}

Electroscrubbing is method developed from classical scrubber by applying electrostatic processes. In electroscrubbers, water droplets are charged oppositely to dust particles and due to electrostatics attraction forces between those two kinds of species, the deposition of dust particles on water droplets is more probable than in the case of inertial scrubber. Penney at 1944 [10] presented for the first time the combination of dry electrostatics precipitator with electroscrubber. The combination of these two different methods of cleaning exhaust gas resulted in higher collection efficiency than for only inertial scrubber. There are three different designs of electroscrubbers: vertical scrubbers with the gas flowing counter-currently or co-currently to the falling droplets, horizontal scrubbers, in which the charged spray is injected cross flowing to the gas, and Venturi scrubber, in which charged spray is injected into the Venturi throat. An example of vertical scrubber with counter-current gas flow is shown in Fig. 3.

The water consumption by an electroscrubber is similar to a Venturi scrubbers for the same gas flow rate, but total collection efficiency for particles smaller than $400 \mathrm{~nm}$ is over $95 \%$ [11], while the collection efficiency for a single droplet, thanks to Coulomb force, is larger than 1 [12].

\subsection{Electrostatic precipitation}

In an electrostatic precipitator (ESP), particles conveyed by exhaust gas are electrically charged and precipitated by electric field generated between discharge electrode of high curvature and collection electrodes with much lower curvature, usually in the form of plates or cylinder. 


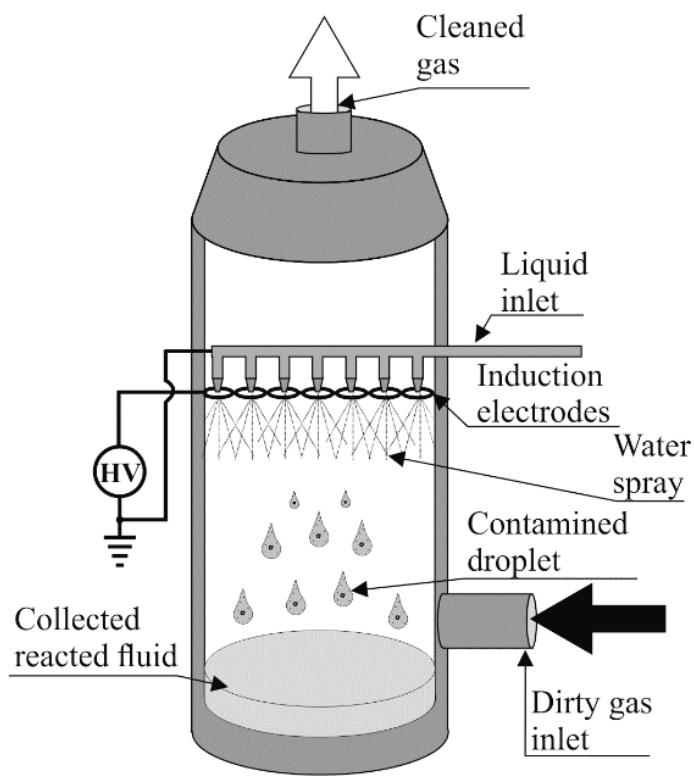

Fig. 3. Vertical type of electroscrubber with counter-current gas flow

Electrostatic precipitation technique for the removal of PM from diesel exhausts was tested by Chan et al. [13], using commercial ESP. Hybrid systems, comprised of an ESP and DPF were tested by Hayashi et al [14], metal foam filter by Kim et al. [15], wet ESP by Saiyasitpanich et al. [16], simple tubular electrostatic filter with corona discharge by Thonglek [17], or without initiation of corona discharge by Kittelson [18].

There is a serious problem with the removal of diesel particles, which have high electric resistivity. Zukeran et al [19] observed that the collection efficiency for particles larger than 1 micron was negative after a certain time of operation, due to the re-entrainment of particles, which were the agglomerates, formed at the collection electrode. These larger particles were easier re-entrained by the flowing gas than the smaller ones.

In this situation, the hybrid system and wet ESP are better solutions, where additional filter and wetting collection electrodes counteracts the re-entrainment, and helps increasing the collection efficiency of PM.

Hayashi et al [14] achieved better collection efficiency using combination of ESP and DPF. Their hybrid system improved the precipitation of PM, compared to a DPF operating alone. The addition of ESP before DPF resulted in decreasing the concentration of particles close to $100 \%$.

\subsection{Electrostatic agglomeration}

Agglomeration is a process by which individual particles are stuck together to form permanent connection between them after their collision. The size of an agglomerate is larger than the individual primary particles. The agglomeration is used for easier removal of submicron particles from the flowing gas by conventional gas cleaning devices, because agglomerates, as large particles, are precipitated with high collection efficiency.

The agglomeration process was also applied to diesel particles. Three type of agglomerators have been developed and tested in the literature: acoustic agglomerators, chemical agglomerators and electrostatic agglomerators. With respect to physical principle, two main types of electrostatic agglomerators can be distinguished:

1) Bipolar agglomerator, in which the particles conveyed by two equal gas streams are charged oppositely, flowing through two parallel prechargers. Agglomeration occurs during mixing of these two streams with the assistance of DC or AC electric fields [20]. In another version, flowing particles can be charged in AC corona discharge, forming oppositely charged particles 
clouds, which are agglomerated due to Coulomb attraction [21].

2) Unipolar agglomerator, in which all particles are charged to the same polarity; and are forced to collision by an AC electric field causing oscillatory motion of these particles. Large particles of higher charge oscillate with large amplitude are scavenging small particles of low mobility. This type of agglomeration is called the kinematic agglomeration [22].

During and after particle collisions, a wide variety of adhesive forces that act between particles, including adsorptive adhesion due to the van der Waals attraction, electrostatic adhesion due to Coulomb force (bipolar charging) and image force (unipolar charging) of charged particles, and liquid bridge force due to a water layer filling the space between particles, which promoted agglomeration of submicron particles.

Probably the first agglomerator for the application to the collection of soot particles exhausted by Diesel engine was proposed by Masuda and Moon [23]. The agglomerator was tested as the first stage, followed by a moving-belt electrostatic precipitator. The overall collection efficiency of this system for PM1 particles was higher than 95\%, for gas velocity lower than $1 \mathrm{~m} / \mathrm{s}$ and dust loading of $120 \mathrm{mg} / \mathrm{m}^{3}$.

Similar solution for removing PM using agglomeration phenomena was tested at the Faculty of Marine Engineering, Gdynia Maritime University. Scheme of the experimental set-up for the investigation of agglomeration and precipitation of PM from exhaust diesel gas is shown in Fig. 4. The stand comprised of precharger/agglomerator and electrostatic precipitator (ESP). The inlet gas temperature was $100^{\circ} \mathrm{C}$. Experiments were carried out for fuels with sulphur content of $0.166 \%$ as fuel for a 2-stroke $73 \mathrm{~kW}$ diesel engine. Total gas flow rate was $980 \mathrm{~m}^{3} / \mathrm{h}$. The agglomerator allowed increasing the removal efficiency from diesel exhausts for PM2.5 by about $12 \%$, compared to electrostatic precipitator operating without agglomerator, and the average total mass collection efficiency was above $74 \%$ for particles smaller than 1 micron.

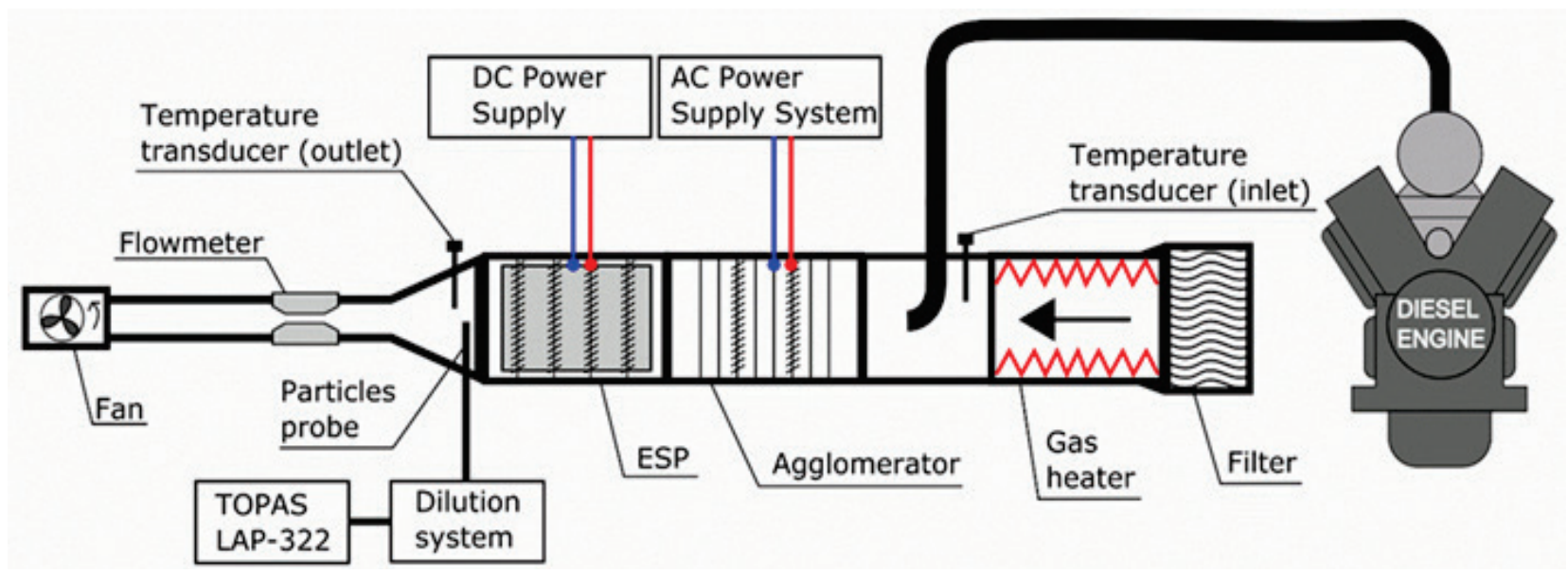

Fig. 4. Scheme of set-up used for agglomeration and collection of PM from diesel exhausts

\section{Conclusions}

It has been show in this article that the electrohydrodynamic methods can be effectively applied to the removal of PM from marine diesel engines. Electrohydrodynamic methods were compared to classical methods. Compared to non-electrostatic scrubbers, inertial and Venturi scrubbers, where collection efficiency for submicron particles is below $70 \%$, the collection efficiency of electroscrubber for PM was over $95 \%$ for submicron particles. In the case of electrostatic precipitator, using a hybrid system comprising an ESP combined with electrostatic agglomerator as the first stage, the mass collection efficiency for PM was higher by about $12 \%$, and was above $74 \%$, compared to ESP operating alone. These technologies are developed to meet the future IMO regulations regarding the PM emission reduction from marine vessels. 


\section{Acknowledgements}

This article was supported by the National Centre for Research and Development (NCBiR) of Poland within the project No. 208429 ELAGLOM "Innovative method for submicron particles emission reduction in flue and exhaust gases".

\section{References}

[1] Ma, H., Steernberg, K., Riera-Palou, X., Tait, N., Well-to-wake energy and greenhouse gas analysis of SOX abatement options for the marine industry, Transport. Res., Part D 17, pp. 301-308, 2012.

[2] http://www.imo.org/en/MediaCentre/IMOMediaAccreditation/Pages/MEPC-74-media-infor mation.aspx.

[3] Richter, H., Howard, J. B., Formation of polycyclic aromatic hydrocarbons and their growth to soot-a review of chemical reaction pathways, Prog. Energy Combust. Sci., Vol.26, pp. 565-608, 2000.

[4] Jaworek, A., Szudyga, M., Krupa, A., Czech, T., Sobczyk, A. T., Marchewicz, A., Antes, T. Balachandran, W., Beleca, R., Di Natale, F. Carotenuto, C., D’Addio, L., Lancia, A., Gregory, D., Jackson, M., Kozak, S., Volpe, L., Charchalis, A., Technical issues of PM removal from ship diesel engines. Transp. Res. Arena., 2014.

[5] Di Natale, F., Carotenuto, C., D’Addio, L., Jaworek, A., Krupa, A., Szudyga, M., Lancia, A., Capture of fine and ultrafine particles in a wet electrostatic scrubber, J. Environ. Chem. Eng. Vol. 3, pp. 349-356, 2015.

[6] Zhu, M., Li, K. X., Shi, W., Lam, J. S. L., Incentive policy for reduction of emission from ships: A case study of China, Marine Policy, Vol. 86, pp. 253-258, 2017.

[7] Sharifi, A., Mohebbi, A., A combined CFD modeling with population balance equation to predict pressure drop in venturi scrubbers, Res. Chem. Intermed., Vol. 40, No. 3, pp. 1021-1042, 2014.

[8] Bianchini, A., Pellegrini, M., Rossi, J., Saccani, C., Theoretical model and preliminary design of an innovative wet scrubber for the separation of fine particulate matter produced by biomass combustion in small size boilers, Biomass Bioenergy, Vol. 116, pp. 60-71, 2018.

[9] Aragon, E., Woillez, J., Perice, C., Tabaries, F., Sitz, M., Corrosion resistant material selection for the manufacturing of marine diesel exhausts scrubbers, Mater. Des., Vol. 30, pp. 1548-1555, 2009.

[10] Penney, G. W., Electrified liquid spray dust-precipitators, U.S. Patent, Editor, 1944.

[11] Di Natale, F., Carotenuto, C., Manna, L., Esposito, M., La Motta, F., D’Addio, L., Lancia, A., Water Electrified Sprays for Emission Control in Energy Production Processes, IJHT, Vol. 34, Special Issue 2, pp. S597-S602, 2016.

[12] Jaworek, A., Balachandran, W., Krupa, A., Kulon, J., Lackowski, M., Wet Electroscrubbers for State of the Art Gas Cleaning, Environ. Sci. Technol., Vol. 40, No. 20, pp. 6197-6207, 2006.

[13] Chan, T. L., Lee, P. S., Siak, J. S., Diesel-Particulate Collection for Biological Testing. Comparison of Electrostatic Precipitation and Filtration, Environ. Sci. Technol., Vol. 15, No. 1, 1981.

[14] Hayashi, H., Takasaki, Y., Kawahara, K., Takashima, K., Mizuno, A., Electrostatic Charging and Precipitation of Diesel Soot, IEEE Trans. Ind. Appl., Vol. 47, No. 1, pp. 331-335, 2011.

[15] Kim, H. J., Han, B., Woo, C. G., Kim, Y. J., Submicron PM Removal of an ESP Combined with a Metallic Foam Filter for Large Volumetric Diesel Engines, IEEE Trans. Ind. Appl., Vol. 51, No. 5, pp. 4173-4179, 2015.

[16] Saiyasitpanich, P., Keener, T. C., Khang, S. J., Lu, M., Removal of diesel particulate matter (DPM) in a tubular wet electrostatic precipitator, J. Electrostat., Vol. 65, pp. 618-624, 2007. 
[17] Thonglek, N., Dechthummarong, C., Kiatsiriroat, T., Soot Treatment by Using High Voltage Pulse Energized Electrostatic Precipitator, Energy Procedia, Vol. 9, pp. 292-298, 2011.

[18] Kittelson, D. B., Further studies of electrostatic collection and agglomeration of diesel particles, SAE Trans., Vol. 100, pp. 454-471, 1991.

[19] Zukeran, A., Ikeda, Y., Ehara, Y., Matsuyama, M., Ito, T., Takahashi, T., Kawakami, H., Takamatsu, T., Two-Stage-Type Electrostatic Precipitator Re-Entrainment Phenomena Under Diesel Flue Gases, IEEE Trans. Ind. Appl.,, Vol. 35, No. 2, pp. 346-351, 1999.

[20] Jaworek, A., Marchewicz, A., Sobczyk, A. T., Krupa, A., Czech, T., Two-stage electrostatic precipitator with dual-corona particle precharger for PM2.5 particles removal. J. Clean. Prod., Vol. 164, pp. 1645-1664, 2017.

[21] Jaworek, A., Marchewicz, A., Sobczyk, A. T., Krupa, A., Czech, T., Two-stage electrostatic precipitator with co- and counter-flow particle prechargers, J. Electrostat., Vol. 87, pp. 180-194, 2017.

[22] Sobczyk, A. T., Marchewicz, A., Krupa, A., Jaworek, A., Czech, T., Śliwiński, Ł., Kluk, D., Ottawa, A., Charchalis, A., Enhancement of collection efficiency for fly ash particles (PM2.5) by unipolar agglomerator in two-stage electrostatic precipitator, Sep. Purif. Technol., Vol. 187, pp. 91-101, 2017.

[23] Masuda, S., Moon, J. D., Electrostatic Precipitation of Carbon Soot from Diesel Engine Exhaust, IEEE Trans. Ind. Appl., Vol. IA-19, No. 6, pp. 1104-1111, 1983. Manuscript received 04 July 2019; approved for printing 20 September 2019 